\title{
SOBRE LA RESPONSABILIDAD CIVIL POR CAMBIO CLIMÁTICO EN CHILE ${ }^{1}$
}

\begin{abstract}
Cristián Banfi del Río
Resumen: La comunidad científica coincide en que la emisión de gases de efecto invernadero genera calentamiento global y éste a su vez produce cambio climático. El cambio climático está y seguirá causando daños graves, incluso catastróficos, a la salud de las personas y al medioambiente. En este contexto, este artículo argumenta que la responsabilidad civil extracontractual puede contribuir en las tareas de mitigación y adaptación relacionadas con el daño que emana del cambio climático. Sin embargo, para lograr este objetivo, en futuros juicios indemnizatorios por cambio climático en Chile, los demandantes deberán proporcionar a los tribunales evidencia que demuestre la existencia de un nexo causal directo y necesario entre las emisiones de gases de efecto invernadero — producidas por una o más personas naturales o jurídicas- y el dańo concretamente sufrido por la víctima.
\end{abstract}

Palabras clave: gases de efecto invernadero, cambio climático, responsabilidad civil extracontractual, juicios indemnizatorios

\section{On tort liability for climate change in Chile}

\begin{abstract}
The scientific community agrees that the emission of greenhouse gases generates global warming which in turn produces climate change. Climate change is -and will continue- causing serious, even catastrophic harm to the people's health and the environment. In this context, this article argues that tort liability can make a contribution to the mitigation and adaptation efforts related to the harm arising from climate change. In order to achieve this aim in future tort litigation for climate change in Chile, however, the claimants will have to provide courts with evidence showing the existence of a direct and necessary causal link between the emissions of greenhouse gases - produced by one or more natural persons or legal entities- and the harm actually suffered by the victim.
\end{abstract}

Key words: greenhouse gases, climate change, tort liability, tort litigation

\section{Sobre a responsabilidade civil por mudança climática no Chile}

Resumo: A comunidade científica concorda que a emissáo de gases de efeito estufa gera aquecimento global e este por sua vez produz mudança climática. A mudança climática está e seguirá causando danos graves, inclusive catastróficos, à saúde das pessoas e ao meio ambiente. Neste contexto, este artigo argumenta que a responsabilidade civil extracontratual pode contribuir nas tarefas de mitigaçáo e adaptação relacionadas com o dano que emana da mudança climática. Sem dúvida, para alcançar este objetivo, em juízos indenizatórios futuros pela mudança climática no Chile, os demandantes deverão proporcionar aos tribunais evidência que demonstre a existência de um nexo causal direto e necessário entre as emissóes de gases de efeito estufa - produzidos por uma ou mais pessoas físicas ou jurídicas - e o dano concretamente sofrido pela vítima.

Palavras chave: gases de efeito estufa, mudança climática, responsabilidade civil extracontratual, juízos indenizatórios

1 Este artículo integra el Proyecto Fondecyt Regular 1170094.

2 University of Cambridge. Profesor Asociado de Derecho Civil, Facultad de Derecho, Universidad de Chile, Chile

Correspondencia: cbanfi@derecho.uchile.cl 


\section{Introducción}

Existe consenso científico mundial de que la emisión de gases de efecto invernadero (GEI), en particular dióxido de carbono $\left(\mathrm{CO}_{2}\right)$ proveniente de actividades humanas (antropogénicas) causa calentamiento global; éste produce cambio climático y, a su vez, este último acarrea daños severos y acumulativos para las actuales y futuras generaciones. El mismo pone en riesgo el acceso al agua, la producción de alimentos, la salud, la utilización de las tierras y el medioambiente(1). En este sentido, el Panel Intergubernamental para el Cambio Climático (IPCC, sigla inglesa) afirma tener "un 95\% de certeza de que la actividad humana es la causa principal del calentamiento global"; que "cuanto mayor sea la perturbación de la actividad humana sobre el clima, mayores serán los riesgos de impactos graves, generalizados e irreversibles en las personas y los ecosistemas, y más duraderos serán los cambios en todos los componentes del sistema climático"; que "disponemos de los medios para limitar el cambio climático y sus riesgos, y de muchas soluciones que permiten el continuo desarrollo económico y humano. Sin embargo, para estabilizar el aumento de la temperatura por debajo de $2^{\circ} \mathrm{C}$ respecto de los niveles preindustriales, será necesario un cambio radical y urgente del statu quo"; y que "cuanto más esperemos a actuar, mayores serán el costo y los desafíos tecnológicos, económicos, sociales e institucionales que enfrentaremos" (2).

El cambio climático es un problema cultural que plantea complejos desafíos para todas las áreas del saber, entre las que destacan la ética ambiental(3,4) y el Derecho(5). Los instrumentos jurídicos internacionales - como la Convención Marco de las Naciones Unidas sobre el Cambio Climático (1992) y el Protocolo de Kyoto (1998) - y las regulaciones domésticas afrontan el cambio climático mediante dos acciones centrales: la mitigación o reducción de los GEI tendiente a limitar el cambio climático futuro, y la adaptación o atenuación de los impactos que aquél causa en ecosistemas y comunidades(6). Estas estrategias ayudan a disminuir el riesgo y evitar, acotar o retardar los efectos negativos del cambio climático. Sin embargo, la ejecución de medidas de adaptación se hace cada vez más difícil, pues el cambio climático — como su nom- bre lo indica - es un estado en constante evolución, incierto e inestable(7). De ahí la necesidad de desarrollar la resiliencia o capacidad para reaccionar ante los riesgos —en particular de desastres naturales - creados por el fenómeno, disminuirlos y persistir $(8,9)$.

El cambio climático — como ciertas patologías graves (cardiovasculares, cancerígenas, respiratorias), epidemias, catástrofes naturales, crisis financieras o desastres nucleares - es un riesgo difuso, sinérgico e impredecible(10).

Con todo, se aprecia la existencia de un continuo entre la emisión de GEI, el calentamiento global, el cambio climático y los daños para las personas (vida, salud, propiedad) y el medioambiente. En esta cadena causal, el cambio climático acarrea aluviones e inundaciones, deforestación, huracanes, incendios, derretimiento de masas de hielo, aumentos en el nivel del mar, sequías, enfermedades crónicas o fatales, etc. En suma, el cambio climático destruye ecosistemas, tierras, viviendas, negocios y estilos de vida.

Más importante aún, el origen antropogénico del cambio climático y los efectos nocivos que éste proyecta sobre el entorno y las personas, revela una grave y permanente transgresión de los deberes éticos fundamentales de la humanidad en particular, de los países e industrias que más GEI emiten - para con el medioambiente, los ecosistemas naturales, y las actuales y futuras generaciones. Siguiendo un razonamiento lógiconormativo, a continuación argumentaré que la responsabilidad civil es un instrumento de Derecho privado que no solo puede aportar, directamente, a atenuar los daños ambientales y personales que la violación de los deberes ético-ambientales acarrea, sino también —indirectamente — a disuadir a sus potenciales infractores. Luego, la responsabilidad civil deviene un medio útil para reivindicar los valores éticos, tan olvidados hoy, que deberían orientar la relación armónica entre el ser humano y el entorno.

\section{Función de la responsabilidad civil en relación con el cambio climático}

Si se asume que la ética ambiental aboga por el reconocimiento de deberes morales del ser huma- 
no para con su entorno(3), es claro que el cambio climático se sitúa en el núcleo de la discusión de esta disciplina. El cambio climático se erige en el epítome o en la expresión más conspicua del quebrantamiento - deliberado o al menos negligente- de los deberes ético-ambientales por parte de los principales agentes emisores de GEI; al extremo que este fenómeno no solo implica una amenaza para los ecosistemas naturales y las personas, sino que derechamente les irroga daños devastadores e irreversibles.

En este contexto, cabe preguntarse sobre el rol que un instituto fundamental del Derecho privado - la responsabilidad civil extracontractual y los juicios de indemnización de perjuicios a que ella dé lugar - debería desempeñar en Chile, frente a los daños que su población está expuesta a sufrir como consecuencia directa del cambio climático e indirecta de las emisiones de GEI provenientes de industrias u otros sectores. Ante la ausencia de doctrina y jurisprudencia chilena sobre esta problemática, es oportuno referirse, de modo preliminar, al aporte que la responsabilidad civil y la litigación que se siga de ésta deberían hacer en cuanto atinge a la mitigación y la adaptación frente al cambio climático.

El Derecho privado en general y la responsabilidad civil extracontractual en particular, están fundados en la justicia correctiva. El fin esencial de la responsabilidad civil es reparar el daño que un sujeto sufre a raíz del hecho ilícito perpetrado por otro $(11,12)$. La responsabilidad civil no está disenada para implementar políticas públicas, alcanzar la justicia distributiva, prevenir los accidentes ni sancionar al autor de los daños, sino que constituye un mecanismo ex post o resarcitorio de daños ya inferidos(13).

Luego, la responsabilidad civil solo puede servir de medio auxiliar en la consecución de funciones distributivas, como son la mitigación y la adaptación de los efectos nocivos que el cambio climático conlleva. Sin embargo, por modesta que sea o parezca su contribución en este ámbito, la responsabilidad civil puede aportar a la reafirmación de los principios y valores ético-ambientales, los cuales, pese a hallarse en la base de la legislación ambiental(14), son constantemente ignorados y vulnerados por los principales agentes del calentamiento global.
Ahora bien, la reparación de los daños que las personas puedan sufrir a raíz del cambio climático, que es consecuencia del calentamiento global y éste de las emisiones de GEI, solo será factible si las futuras víctimas logran acreditar en el juicio indemnizatorio respectivo tres requisitos - especialmente complicados en esta área - que serán explicados a continuación.

\section{Debe existir un daño cierto}

En primer lugar, la responsabilidad civil supone un daño efectivo. Es decir, la mera creación de un riesgo, como la eventualidad de ser afectado por emisiones de GEI, no configura un daño que gatille la responsabilidad civil. La víctima (demandante) debe demostrar que experimentó un daño real o, al menos, uno potencial respecto del que exista una probabilidad razonable o suficiente rayana en la certeza - de que sobrevendrá(15). Por ende, el riesgo será tomado en cuenta solo si se actualiza y convierte en un daño cierto, sea este material (daño emergente, lucro cesante, pérdida de la chance) o moral (dolor, angustia, aflicción). Antes que ello ocurra, el riesgo es permitido por el Derecho(16).

Cuestión distinta es la posibilidad de atribuir objetivamente a un sujeto, como suyos(17), los daños consecuentes, en la medida que su conducta culpable haya incrementado el riesgo (en términos de probabilidad e intensidad) de que los daños sobrevinieran. Luego, el autor deberá responder del daño en la medida que éste concrete un riesgo extraordinario, mientras que no deberá hacerlo si el daño materializa un riesgo general u ordinario de la vida, que integra el curso normal de los acontecimientos(13).

Sin embargo, la emisión de GEI inequívocamente produce calentamiento terrestre, éste causa cambio climático y esto último aumenta el riesgo de daño, tanto para las personas como para el entorno. Luego, aun cuando sin un daño cierto no es posible atribuir responsabilidad civil a los emisores de GEI, la sola presencia de reglas de responsabilidad (como son los artículos 2.314 y siguientes del Código Civil chileno) puede jugar una importante función disuasiva. En efecto, dichas normas comunican a sus destinatarios el mensaje de que todo quien padezca dańos imputables 
al cambio climático podrá reclamar su compensación a uno o más emisores de GEI. Así, esta contingencia puede incentivar a los potenciales demandados a reducir el nivel de sus emisiones o invertir en medidas de adaptación. De esta forma, la responsabilidad civil puede cumplir — junto a su rol resarcitorio preeminente- una importante función preventiva $(18,19)$.

\section{La emisión de GEI debe constituir una infrac- ción del deber de cuidado del demandado}

En segundo lugar, es preciso definir el deber de cuidado exigible a los emisores de GEI y acreditar su infracción. En efecto, la transgresión de ese deber es lo que constituye la culpa, requisito esencial para imputar al agente la obligación de indemnizar los dańos infligidos a la víctima, que en este caso estarán asociados con el cambio climático(20).

La necesidad de establecer un deber de cuidado obedece al hecho de que el estatuto común y supletorio de responsabilidad civil en Chile es la responsabilidad culpa (artículos 2.314 y siguientes del Código Civil). Nuestro ordenamiento jurídico solo consagra reglas específicas de responsabilidad estricta, como el derrame de hidrocarburos y los accidentes nucleares(21), entre las cuales no figura la responsabilidad por daño ambiental ni por emisiones de GEI.

Por cierto, la infracción de las normas o regulaciones específicas que fijan el umbral de emisiones de GEI permitido constituye por sí sola culpa y dará lugar a la responsabilidad civil en la medida que exista una relación de causalidad entre dicha infracción y el daño(15). Fuera de esta situación, sin embargo, por regla general, el deber de cuidado debe ser determinado por el propio juez que conoce del litigio de responsabilidad, mediante el examen y la ponderación de distintos factores indiciarios de la negligencia, como son la intensidad y la probabilidad del dańo; la trascendencia (cultural, económica, ética, política, social, etc.) de la actividad que causa el daño; los costos de disminuir el riesgo o de prevenir el daño, y la relación entre el autor del daño y la víctima(13).

Entre estos elementos, en el presente caso ocupa un lugar destacado el análisis de costos y be- neficios, por cuanto permitirá al juez concluir, retrospectivamente, que el demandado incurrió en negligencia si el costo de prevenir el daño fue menor a la intensidad de éste multiplicada por su probabilidad $(22,23)$. De esta forma, el análisis de costos y beneficios puede influir poderosamente en la decisión que adopten los emisores de GEI sobre qué conducta observar en el futuro. En efecto, como la magnitud de los daños que emanan del cambio climático suele ser inmensa — dada su naturaleza catastrófica(24) — y como la probabilidad de que ellos deriven indirecta o remotamente de la emisión de GEI es elevada, el comportamiento razonable que cabe esperar de los emisores de GEI es que se esfuercen en disminuir, incluso drásticamente, el nivel de contaminación generado. En consecuencia, si estos agentes omiten observar ese estándar de cuidado y el daño acaece, el juez llamado a dirimir el juicio indemnizatorio tendrá la vía relativamente expedita para calificar como negligente la conducta del emisor de GEI y -acreditado el nexo causal entre la emisión y el daño- podrá condenarlo a indemnizar los perjuicios ocasionados a la víctima.

Es más, la emisión de GEI podría ser considerada como un acto doloso - esto es, cometido con la intención de dañar-, ya que su autor contribuye conocida y deliberadamente al calentamiento global, fenómeno que - según la opinión científica asentada - previsiblemente causa cambio climático y éste, a su turno, produce daños personales y ambientales enormes. En este sentido, cabe notar que quien actúa intencionalmente posee un mayor grado de control sobre su acto y efectos que quien obra imprudentemente. En principio, entonces, el comportamiento deliberado — como podría serlo la emisión de GEI- incrementa incluso más el riesgo de daño (en términos que aumenta su probabilidad de ocurrencia) que un acto meramente culpable $(17,25,26)$.

\section{Debe existir un vínculo causal directo entre la emisión de GEI por uno o más agentes concre- tos y el daño específico sufrido por la víctima}

En tercer lugar, he aquí el nudo gordiano del asunto, es indispensable que el demandante acredite la existencia de una relación de causa a efecto - directa y necesaria - entre la emisión de GEI realizada por unos o más sujetos determinados 
(por ejemplo, una compañía petrolera, carbonífera, generadora eléctrica, automotriz, etc.) y el daño concreto que aquél reclama(27).

Como aseveró un fallo judicial norteamericano, posterior al huracán Katrina: "Cabe prever problemas probatorios desalentadores para todo quien intente demostrar, mediante preponderancia de la evidencia, el grado en que el calentamiento global es causado por la emisión de gases de efecto invernadero; la proporción en que las acciones de cualquiera compañía petrolera o química particular, o la actuación conjunta de estas corporaciones, contribuye, mediante la emisión de gases de efecto invernadero, al calentamiento global; y la extensión en que la emisión de gases de efecto invernadero por dichos demandados, a través del fenómeno del calentamiento global, intensificó o afectó de otra manera el sistema climático que produjo el huracán Katrina” (28).

Desde un punto de vista empírico, físico, material o natural, es ostensible un continuo entre la emisión de GEI, el calentamiento global, el cambio climático y los daños que éste causa. La conexión entre ambos extremos o polos puede sustentarse en el más simple test de causalidad, a saber, la equivalencia de las condiciones o but for test(29). Desde esta perspectiva, puede decirse que, en principio, la emisión de GEI es una condición sin la cual no habría calentamiento global, cambio climático ni daños consiguientes.

Empero, desde un punto de vista jurídico, es necesario que el daño sea normativa u objetivamente imputable al emisor de GEI. Para ello es menester recurrir a otras explicaciones causales, como la tesis de la causa adecuada, la que prescribe que el autor responde de los daños que corriente, normal u ordinariamente pueden atribuírsele como consecuencia de su actuar, ya que son previsibles para una persona de mediana diligencia puesta en su lugar(30). Pero es aquí donde las dudas pueden emerger. Porque es factible que el daño invocado por la víctima haya escapado al curso normal de los acontecimientos y sea un resultado extraordinario e imprevisible, no susceptible de ser imputado al emisor de GEI demandado.

Pero la causalidad tiene un inconveniente adicional. Supóngase que los daños que sufre la víctima y que derivan del cambio climático puedan imputarse a dos o más emisores de GEI. En nuestro Derecho, si las emisiones de GEI corresponden a una sola y misma conducta, ejecutada por distintos agentes, éstos deben responder solidariamente de los daños (artículo 2.317 del Código Civil). Sin embargo, esta regla no resuelve un problema diferente: cuando, concurriendo varios agentes a producir el daño, no es posible - científica ni jurídicamente- identificar a su autor o autores. Peor aún, los GEI son acumulativos y sus perniciosas secuelas suelen tener un largo periodo de latencia hasta su completa manifestación, lo que dificulta sobremanera - o incluso impide- probar el nexo causal entre unas emisiones específicas de GEI y unos dańos concretos(20).

Frente a tal situación, tal vez debería contemplarse la posibilidad de declarar responsables a los emisores de GEI involucrados en la producción del daño, en proporción a la participación de cada uno de ellos en el mercado relevante. Es lo que sucedió en el célebre caso Sindell v. Abott Laboratories. La Corte de California condenó a once laboratorios demandados - fabricantes del dietilestilbestrol (DES) — a resarcir los daños sufridos por la demandante, cuya madre, estando embarazada, consumió ese fármaco a fin de prevenir un aborto espontáneo, tratamiento habitual en la década de 1960. A consecuencia de ello, la hija demandante en el juicio en comento- desarrolló un cáncer. Sin embargo, a pesar de que en el litigio no se acreditó cuál de los demandados elaboró el DES concretamente ingerido por la madre de la demandante, la corte declaró responsables de los dańos a todos los laboratorios demandados que habían utilizado idéntica fórmula, pues estimó que los demandados estaban en mejor posición que la actora para asumir los costos derivados del daño causado por el producto defectuoso. Al efecto, la corte ordenó a cada demandado pagar a la víctima una suma de dinero proporcional a la cuota que cada uno de ellos tenía en el mercado de producción de DES(31).

En suma, la posibilidad de hacer responder a los emisores de GEI de los daños que causan al medioambiente y las personas, presupone que las víctimas logren demostrar los requisitos antes descritos, lo que representa un serio desafío. Con todo, la sola vigencia de las reglas sobre responsa- 
bilidad civil cumple una función disuasiva, que contribuye al reconocimiento y eventual respeto de los valores ético-ambientales que subyacen a las leyes y regulaciones ambientales. En este sentido, las normas sobre responsabilidad civil debieran operar como un incentivo para que sus destinatarios adopten las medidas efectivas de mitigación y adaptación ante el cambio climático, que surgen como una necesidad ética ineludible.

\section{Conclusión}

Es previsible que los daños que las personas y el medioambiente están sufriendo en Chile, como consecuencia directa del cambio climático e indirecta de las emisiones de GEI - los que, con seguridad, aumentarán en intensidad y frecuencia para mal de las futuras generaciones-, den lugar a juicios de responsabilidad civil extracontractual.

Sin embargo, la posibilidad de que la responsabilidad civil contribuya efectivamente a la mitigación y la adaptación de los efectos del cambio climático dependerá de que, en cada litigio que se promueva, se acredite la existencia de un daño cierto concretamente sufrido por la víctima; la infracción de un deber de cuidado por parte del emisor o emisores de GEI demandados, y, en particular, la relación de causalidad entre dicha infracción y aquel daño.
Sin ser pesimistas, manifestamos nuestro escepticismo sobre las perspectivas de éxito para las actuales y futuras víctimas del cambio climático asociado al calentamiento global y este último a las emisiones de GEI. Creemos que los jueces nacionales deberían estar abiertos a la posibilidad de aplicar soluciones que, sin transgredir las reglas jurídicas vigentes, permitan atribuir, de manera justa, la responsabilidad por los daños derivados del cambio climático a quienes los han causado, descartándose en principio que dicho fenómeno sea un caso fortuito.

Una de estas soluciones, entre varias otras que deberán investigarse, consiste en aplicar una regla de responsabilidad proporcional, o market share liability, en situaciones con pluralidad de demandados, por ejemplo, en un eventual pleito que inicie un grupo de personas afectadas por contaminación industrial en contra de diversas compañías emisoras de GEI que operan en la zona donde las primeras habitan. Lo anterior, supuesto que se acredite que el daño sufrido por las víctimas - proveniente de la toxicidad de los elementos presentes en el aire que inhalan - puede ser imputado, con una probabilidad razonable (no menos del 50\%), precisamente a la actividad industrial de las empresas demandadas que operan en el área. 


\section{Referencias}

1. Stern N. The Economics of Climate Change: The Stern Review. Cambridge, UK: Cambridge University Press; 2007: vi.

2. IPCC, editor. Cambio climático 2014. Informe de sintesis. Genève: IPCC; 2015: 4.

3. Kawall J. A history of environmental ethics. In Gardiner S, Thompson A, editors. The Oxford handbook of environmental ethics. Oxford: Oxford University Press; 2017: 20.

4. Kingston S, Heyvaert V, Cavoski A. European environmental law. Cambridge: Cambridge University press; $2017: 47$.

5. Carlane C. Climate change, law and policy. Oxford: Oxford University Press; 2010: 4.

6. Farber D. Climate change, federalism, and the Constitution. Arizona Law Review 2008; 50: 881.

7. Rosso M. Climate change and the law. American Journal of Comparative Law 2010; 58: 252.

8. Holling C. Resilience and the stability of ecological systems. Annual Review of Ecology and Systematics 1973; 4: 1-23.

9. Hutter B. Risk, resilience and inequality: current dilemmas in environmental regulation. In Hutter B, editor. Risk, resilience, inequality and environmental law. Cheltenham: Edward Elgar Publishing; 2017: 22-24.

10. Jasanoff S. Constitutions of modernity: science, risk and governable subjects. In Wiemer, M, De Ruijter A, editors. Regulating risks in the European Union. Oxford: Hart Publishing; 2017: 20.

11. Aristóteles. Ética Nicomaquea. (trad. Samaranch, F.). Segunda edición. Madrid: Ediciones Aguilar; 1977: L. V, Cap. 4, 1229.

12. Weinrib E. Idea of private law. Oxford: Oxford University Press; 2012: 1-21.

13. Barros E. Tratado de responsabilidad extracontractual. Santiago de Chile: Editorial Jurídica de Chile; 2006: 33-43, 105-119, 236-238, 401-404.

14. Flournoy A. In search of an environmental ethic. Columbia Journal of Environmental Law 2003: 63-118.

15. Alessandri A. De la responsabilidad extracontractual en el derecho civil chileno. Santiago de Chile: Imprenta Universitaria; 1943 : 175, 214-215.

16. Esteve J. Técnica, riesgo y derecho. Tratamiento del riesgo tecnológico en el derecho ambiental. Barcelona: Editorial Ariel; 1999: 37-38.

17. García-Ripoll M. Imputación objetiva, causa próxima y alcance de los daños indemnizables. Granada: Editorial Comares; 2008: 51, 65-66.

18. Lawson F, Markesinis B. Tortious liability for unintentional harm in the common law and the civil law. Cambridge: Cambridge University Press 1982: 180-181.

19. Owen, D. The fault pit. Georgia Law Review 1992: 717.

20. Hunter D, Salzman J. Negligence in the air: the duty of care in climate change litigation. University of Pennsylvania Law Review 2007; 155(6): 1741-1794.

21. Corral, H. Lecciones de responsabilidad civil extracontractual. Segunda edición. Santiago de Chile: Thomson Reuters; 2013: 219-220.

22. United States v. Carroll Towing Co. 159 F.2d (1947).

23. Deakin S, Johnston A, Markesinis B. Markesinis and Deakin's tort law. Seventh edition. Oxford: Oxford University Press; 2013: 209-214.

24. Moréteau O. Catastrophic harm in United States law: liability and insurance. American Journal of Comparative Law 2010; 58: 69-95.

25. Kenny, A. Intention and purpose. Journal of Philosophy 1966; 63(20): 650.

26. Cane, P. Responsibility and fault: a relational and functional approach to responsibility. En Cane P, Gardner J, editors. Relating to responsibility. Essays for Tony Honoré on his Eightieth Birthday. Oxford: Hart Publishing; 2001: 107.

27. Farber D. Basic compensation for victims of climate change. University of Pennsylvania Law Review 2007; 155(6): $1636-1637$.

28. Comer v. Nationwide Mut. Ins. Co. No. 1:05 CV 436 LTD RHW, 2006 WL 1066645, 4, S.D. Miss. Feb. $23,2006$.

29. Jones MA. Causation in tort: general principles. En Jones MA, editor. Clerk \& Lindsell on torts. Twenty-first edition. London: Thomson Reuters; 2014: 61.

30. Domínguez, R. Aspectos de la relación de causalidad en la responsabilidad civil con especial referencia al derecho chileno. Revista de Derecho Universidad de Concepción 2001; 209: 14-15.

31. Sindell v. Abbott Laboratories 607 P 2d 924 (1980).

Recibido: 5 de abril de 2019

Aceptado: 2 de mayo de 2019 